\title{
Spectrum of Histopathological Diagnosis of Schistosomiasis as a Systemic Parasitic Infection in the North-West Nigeria
}

\author{
Abdullahi kabiru ${ }^{1}$, Rasheed Mumini Wemimo ${ }^{2,}$, , Mohammed Umar ${ }^{1}$, Adegboye Adeyemi Taiwo ${ }^{3}$, \\ Afolayan Enoch Abiodun ${ }^{4}$, Aliyu Salihu ${ }^{5}$ \\ ${ }^{1}$ Departments of Histopathology, Usmanu Danfodiyo University Teaching Hospital, Sokoto, Nigeria \\ ${ }^{2}$ Department of Histopathology, Federal Medical Centre, Birnin-Kudu, Jigawa State, Nigeria \\ ${ }^{3}$ Mojitaiwo Data Services and Data Management Executives (RC-2566098), Ilorin, Kwara state Nigeria \\ ${ }^{4}$ Department of Histopathology, University of Ilorin Teaching Hospital, Ilorin, Kwara State, Nigeria \\ ${ }^{5}$ Department of Morbid Anatomy and Forensic Medicine, Usmanu Danfodiyo University, Sokoto, Nigeria
}

Email address:

kabile08@yahoo.com (A. kabiru), muminirasheed265@gmail.com (R. M. Wemimo)

${ }^{*}$ Corresponding author

\section{To cite this article:}

Abdullahi kabiru, Rasheed Mumini Wemimo, Mohammed Umar, Adegboye Adeyemi Taiwo, Afolayan Enoch Abiodun, Aliyu Salihu. Spectrum of Histopathological Diagnosis of Schistosomiasis as a Systemic Parasitic Infection in the North-West Nigeria. American Journal of Laboratory Medicine. Vol. 5, No. 6, 2020, pp. 180-184. doi: 10.11648/j.ajlm.20200506.15

Received: June 12, 2020; Accepted: June 28, 2020; Published: December 31, 2020

\begin{abstract}
Introduction: Schistosomiasis is one of the neglected tropical diseases transmitted by freshwater snail in the slowmoving water of tropical rivers and ranks second among the most widespread parasitic disease in various nations in subSaharan Africa. Methodology: This is a 10-year retrospective study of all cases of schistosomiasis seen in the Department of Anatomic Pathology, Usmanu Danfodiyo University Teaching Sokoto between January 2008 and December 2017. All the cases of schistosomiasis diagnosed was retrieved from the surgical pathology register. The patients' biodata and symptoms was retrieved from patients' folder. The specimens were processed with 10\% Neutral buffered formalin, stained with Haematoxylin and Eosin and reported by the pathologist at the study centre. The 2016 WHO classification of the urinary system and male genital organs were used to classify the tumours. Results: A hundred and fifty-nine patients were analysed with schistosomiasis of varying systems range from gastrointestinal, prostate, genitourinary and 38 cases of malignancies of the urinary bladder with associated schistosomiasis and prostate. In the gastrointestinal system, the appendiceal schistosomiasis accounted for $21(80.8 \%)$, rectum $3(11.5 \%)$ and sigmoid colon 2 cases $(7.7 \%)$. Benign prostatic hyperplasia with schistosomiasis accounted for 1 case $(25.0 \%)$ while 3 cases $(75.0 \%)$ of prostatic adenocarcinoma with schistosomiasis showed age range of 45 to 78 years. There are one hundred and eleven (111) cases of urinary bladder schistosomiasis which accounted for $86.0 \%$, male to female ratio of 10:1 and age range from 9.0 to 78.0 years. There are 27 cases of invasive squamous cell carcinoma of the urinary bladder associated with schistosomiasis accounted for $65.8 \%$ while adenocarcinoma showed 4 cases (9.7\%). Moderately differentiated SCC accounted for the largest degree of tumour differentiation associated with schistosomiasis accounted for $69.6 \%$. Terminal haematuria is the most common symptom of urinary bladder schistosomiasis accounted for 102 cases (64.2\%), followed by suprapubic abdominal pain 52 (32.5\%), weight loss 30 (18.9\%) for patients with malignancy Conclusion: Schistosomiasis is a public health disease in endemic regions in African countries with proper documentation on the its pathogenesis, risk factors and effective treatment and complications if left untreated. Thus, mobilization of appropriate resources to help the vulnerable in order to reduce morbidity and mortalities is very crucial.
\end{abstract}

Keywords: Schistosomiasis, Adenocarcinoma, Squamous Cell Carcinoma (SCC), Benign Prostatic Hyperplasia, WHO 


\section{Introduction}

Schistosomiasis is one of the neglected tropical diseases transmitted by freshwater snail in the slow-moving water of tropical rivers and ranks second among the most widespread parasitic disease in various nations in sub-Saharan Africa. [1] Globally, an estimated 239 million people are currently infected, with burden of more than 3.5 million disability-adjusted life years. [2] It causes about 534,000 deaths annually in subSaharan Africa. (1) The overall prevalence of urinary schistosomiasis (Schistosoma haematobium) was 60.8\% (228 positive cases in 375 samples), and for intestinal schistosomiasis (Schistosoma mansoni) was $2.93 \%$ (11 positive in 375 samples) [3] There is Global increase of the disease both in prevalence and incidence because of expansion of irrigated Agriculture which provide habitats for vector snails, the construction of hydro-electricity generating sites, lack of good sanitary habits and lack of safe water for the growing population. [1] Schistosomiasis is caused by Schistosoma species transmitted by freshwater snail that live in the slow-moving water of tropical rivers, lakes and irrigation ditches. The prevalence of the infection by water contact activities rank higher among farmer, swimmers, and fishermen which account for $84.87 \%, 78.21 \%$ and $52.17 \%$ respectively. [3]

Similarly, those who contact river and dam water for bathing, fetching and washing had prevalence of $29.03 \%$, $28.57 \%$ and $22.85 \%$ respectively. [3] This diseases exert great health, social and financial burden on economies of households and governments. Intestinal schistosomiasis causes pinhead-sized granulomas in liver, pipe stem fibrosis or liver cirrhosis, portal hypertension, mesangioprolifrative or membranous glomerulopathy and pseudopolyps in the colon while the urinary schistosomiasis has profound pathologic lesions on the urogenital system such as inflammatory cystitis, fibrosis of urethral walls, urinary bladder outlet obstruction, hydronephrosis, chronic pyelonephritis and squamous cell carcinoma. The morbidity and mortality caused by this disease cannot be overemphasized. This review is an exposition of human schistosomiasis as it affects the inhabitants of various communities in sub-Sahara African countries. This review is aim at re-awakening efforts to combat this impoverishing disease in terms of institutionalizing preventive measures and availability of treatment at earlier stage of diagnosis. The aim of this study is to establish spectrum of clinicalhistopathological diagnosis of schistosomiasis as a systemic parasitic infection at North-West Nigeria.

The aims and objective of this study are:

To determine the age of the patients with schistosomiasis

To determine the spectrum of organ involvement of schistosomiasis.

To determine the symptoms of patients with schistosomiasis.

\section{Methodology}

This study was 10-year retrospective type of all cases of schistosomiasis seen in the Department of Anatomic Pathology, Usmanu Danfodiyo University Teaching Sokoto between January 2008 and December 2017. All the cases of schistosomiasis diagnosed was retrieved from the surgical pathology register. The patients' biodata and symptoms was retrieved from patients' folder. The specimens were fixed in $10 \%$ formalin, dehydrated in the ascending grade of alcohol in $70 \%, 80 \%, 90 \%, 100 \%$ and $100 \%$, clearing done with Xylene, and infiltrated with molten Paraffin wax. The tissues was embedded in the stainless embedding mould and subsequently put in cold zone of the embedding machine. The sections were cut at 3.0um with rotatory Leica Microtome. The tissue sections were stained with Haematoxylin and Eosin stain. The H\&E slides was reported by the pathologist at the study centre. The 2016 WHO classification of the urinary system and male genital organs were used to classify the tumours.

\subsection{Inclusion Criteria}

All histologically diagnosed cases of schistosomiasis within the study period between January 2008 to December 2017.

\subsection{Exclusion Criteria}

All Cases with missing data within the study period.

\subsection{Sample Size}

This is a retrospective study. It involved all cases during the 10 years in retrospect that met the inclusion criteria and do not fall within the exclusion criteria.

\subsection{Data Presentation}

Data were analyzed using the IBM- SPSS version 23.0 (IBM corporation, Virginia, U.S.A.) 2015 for Windows software package. The data collected on the proforma were transferred into a master sheet using numerical codes. Continuous variables were expressed as mean and standard deviation (SD), categorical variables as number and percentage. Descriptive statistics was generated and applied along with inferential statistics where applicable.

\section{Results}

A hundred and fifty-nine patients were analysed with schistosomiasis of varying systems range from gastrointestinal, prostate, genitourinary and 40 cases of malignancies of the urinary bladder with associated schistosomiasis and prostate. In the gastrointestinal system, the appendiceal schistosomiasis accounted for $21(80.8 \%)$, rectum 3 (11.5\%) and sigmoid colon 2 cases (7.7\%).

Benign prostatic hyperplasia with schistosomiasis accounted for 1 case $(25.0 \%)$ while 3 cases $(75.0 \%)$ of prostatic adenocarcinoma with schistosomiasis showed age range of 45 to 78 years. This is illustrated in table 2. There are one hundred and eleven (111) cases of urinary bladder 
schistosomiasis which accounted for $86.0 \%$, male to female ratio of 10:1 and age range from 9.0 to 78.0 years. A case of pyelonephritis due to schistosomiasis showed $0.8 \%$ in female at 8 years of age. There are 10 cases of schistosomiasis of the ureter which accounted for $7.7 \%$ in male at age range of 21 to 48 years, 4 cases of urethritis owing to schistosomiasis accounted for $3.1 \%$ in male patients at age range of $29-42$ years and each case of schistosomiasis of the testis, uterine cervix and fallopian tube at varying age range as illustrated in the table 3 .

There are 27 cases of invasive squamous cell carcinoma of the urinary bladder associated with schistosomiasis which accounted for $65.8 \%$, male to female ratio $6: 1$ and the youngest patients was 21 years while the oldest were 70 years. High grade papillary urothelial carcinoma showed 4 cases $(9.7 \%)$ in male patients and the age bracket range from 30 years to 60years. Invasive urothelial carcinoma accounted for 2 cases $(4.9 \%)$ in male patients at age range of 45 to 78 years while adenocarcinoma showed 4 cases $(9.7 \%)$ in male patients at youngest age of 50 years while the oldest was 60 years. There is 1 case $(2.4 \%)$ of cystitis glandularis and carcinoma-in-situ at varying age range as shown in the table 4. Well-differentiated invasive squamous cell carcinoma of the urinary bladder accounted for 5 cases (21.7\%), moderately differentiated 16 cases $69.6 \%$ and poorly differentiated showed 2 cases $8.7 \%$ as illustrated in the table 5. Majority of male patients had welldifferentiated squamous cell carcinoma with male to female ratio of $3: 2$, the youngest was 21 years while the oldest patient were 70 years old. Moderately differentiated squamous cell carcinoma(SCC) for the largest degree of differentiation with male to female ratio $7: 1$, the youngest patient was 28years while the oldest was 70 years. Poorly differentiated SCC was in seen in all males patients and the age range span from 36 years to 60 years. Majority of patients presented with terminal haematuria accounted for 102 cases $(64.2 \%)$, followed by suprapubic abdominal pain $52(32.5 \%)$, weight loss $30(18.9 \%)$ for patients with malignancy. Others symptoms are vomiting, rectal pain, vaginal discharge and lower urinary tract symptoms comprising of irritative and obstructive. This is illustrated in figure 2 .

Table 1. Gastrointestinal schistosomiasis

\begin{tabular}{llllll}
\hline Variables & Frequency & $\%$ & M: F & Age range & Mean age \pm SD \\
\hline Appendix & 21 & 80.8 & $6: 1$ & $5-40$ & $18.38 \pm 8.46$ \\
Rectum & 3 & 11.5 & $3: 0$ & $22-55$ & $34.67 \pm 17.78$ \\
Sigmoid colon & 2 & 7.7 & $2: 0$ & $12-48$ & $30.00 \pm 25.45$ \\
\hline
\end{tabular}

Table 2. Prostatic lesions with schistosomiasis.

\begin{tabular}{llllll}
\hline Variables & Frequency & $\%$ & M: F & Age range & $\begin{array}{l}\text { Mean age } \pm \\
\text { SD }\end{array}$ \\
\hline $\begin{array}{l}\text { BPH with } \\
\text { schistosomiasis }\end{array}$ & 1 & 25.0 & $1: 0$ & $55-55$ & 10 \\
Adenocarninoma & 3 & 75.0 & $3: 0$ & $55-65$ & $60.00 \pm 5.00$ \\
\hline
\end{tabular}

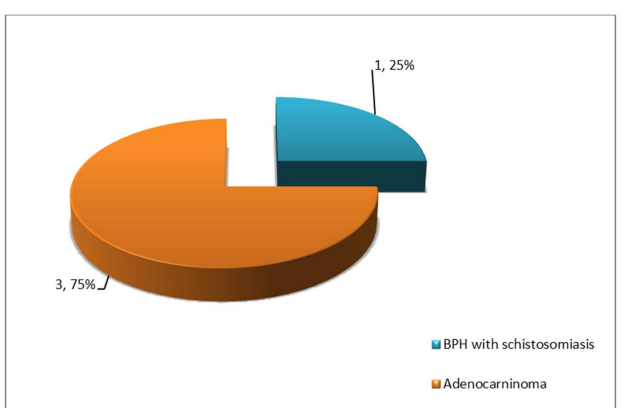

Figure 1. Prostatic lesions with schistosomiasis.

Table 3. Genitourinary schistosomiasis.

\begin{tabular}{|c|c|c|c|c|c|}
\hline Organs & Frequency & $\%$ & M: F & $\begin{array}{l}\text { Age range } \\
\text { (years) }\end{array}$ & $\begin{array}{l}\text { Mean age } \pm \\
\text { SD }\end{array}$ \\
\hline Urinary bladder & 111 & 86.0 & $10: 1$ & $9-78$ & $45.64 \pm 14.87$ \\
\hline $\begin{array}{l}\text { Kidney(Pylonephritis } \\
\text { with schistosomiasis }\end{array}$ & 1 & 0.8 & $0: 1$ & $8-8$ & 8.00 \\
\hline Ureter & 10 & 7.7 & 10:0 & $21-48$ & $36.70 \pm 8.49$ \\
\hline Urethra & 4 & 3.1 & $4: 0$ & $29-42$ & $35.25 \pm 5.32$ \\
\hline Testis & 1 & 0.8 & $1: 0$ & $12-12$ & 12.00 \\
\hline Uterine cervix & 1 & 0.8 & $0: 1$ & $34-34$ & 34.00 \\
\hline Fallopian tube & 1 & 0.8 & $0: 1$ & $25-25$ & 25.00 \\
\hline
\end{tabular}

Table 4. Benign and malignant lesions of the Urinary bladder associated with schistosomiasis.

\begin{tabular}{|c|c|c|c|c|c|}
\hline Diagnosis & Frequency & $\%$ & $\mathbf{M}: \mathbf{F}$ & Age & $\begin{array}{l}\text { Mean age } \pm \\
\text { SD years }\end{array}$ \\
\hline $\begin{array}{l}\text { SCC (Squamous cell } \\
\text { carcinoma) }\end{array}$ & 27 & 65.8 & $6: 1$ & $21-70$ & $49.59 \pm 12.74$ \\
\hline $\begin{array}{l}\text { HGPUC (High grade } \\
\text { papillary urothelial } \\
\text { carcinoma) }\end{array}$ & 4 & 9.7 & $4: 0$ & $30-56$ & $46.50 \pm 11.36$ \\
\hline $\begin{array}{l}\text { IUPC (Invasive } \\
\text { urothelial papillary } \\
\text { carcinoma) }\end{array}$ & 2 & 4.9 & $2: 0$ & $35-55$ & $45.00 \pm 14.14$ \\
\hline Adenocarcinoma & 4 & 9.7 & $4: 0$ & $45-78$ & $58.75 \pm 14.22$ \\
\hline Carcinoma in-situ & 1 & 2.4 & $1: 0$ & $78-78$ & 78 \\
\hline Squamous metaplasia & 3 & 7.3 & $3: 0$ & $46-70$ & $55.33 \pm 12.86$ \\
\hline Cystitis glandularis & 1 & 2.4 & $1: 0$ & $43-43$ & 43 \\
\hline
\end{tabular}

Table 5. Differentiation of SCC of the urinary bladder associated with schistosomiasis.

\begin{tabular}{lllll}
\hline Level of differentiation & Frequency & $\mathbf{\%}$ & M: F & Age range \\
\hline Well differentiated & 5 & 21.7 & $3: 2$ & $21-70$ \\
Moderately differentiated & 16 & 69.6 & $7: 1$ & $28-70$ \\
Poorly differentiated & 2 & 8.7 & $2: 0$ & $36-60$ \\
\hline
\end{tabular}

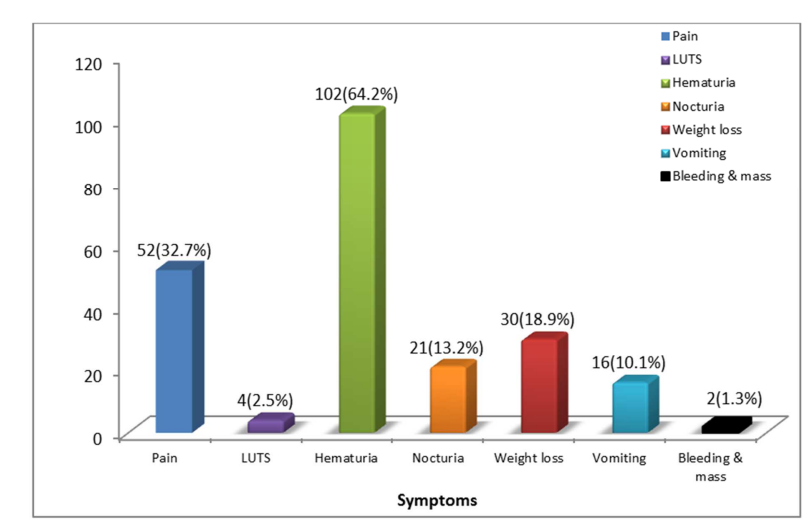

Figure 2. Symptoms of patients with schistosomiasis. 


\section{Discussion}

Schistosomiasis is an acute and chronic parasitic disease caused by blood flukes (trematode worms) of the genus Schistosoma. Estimates show that at least 229 million people required preventive treatment in 2018.(4) Schistosomiasis transmission has been reported from 78 countries where people and communities are targeted for large-scale treatment is required in endemic countries with moderate-to-high transmission. [4] Within the study period, there were 729 appendectomy specimens histologically examined in the Department of Pathology.

Twenty-one of these, representing $2.9 \%$, were diagnosed as schistosomiasis of the appendix. The male: female ratio was $6: 1$, the youngest patients was 5 years while the oldest were 40 years. Schistosomiasis is endemic in many parts of Nigeria with varying regional difference in the incidence of the disease. The incidence of schistosomal appendicitis in this study is $2.9 \%$, which is similar to $2.1 \%$ report by Ahmed et al [5] in Zaria, Northwestern part of the while Gali et al [6] in Maiduguri, Northeastern part Nigeria showed that schistosomal appendicitis accounted for $2.3 \%$. In the Southwestern part of Nigeria in Ibadan, Adebamowo et al [7] showed that it account for $2.4 \%$. There was another report in Lagos, Southwestern part of Nigeria from a 33-year-old female Lagos resident originally from a rural village in Osun state. [8] However, there is serial rise in the incidence of schistosomal appendicitis at Ife in Obafemi Awolowo University Teaching Hospital, lower prevalence was reported in an earlier study comprising of 3 cases $(0.95 \%)$ by Ojo et al [9] followed by Adisa et al [10] showed that 22 cases were seen within study period of 1989-2006 which account for $2.3 \%$ and Badmos et al [11] reported on 35 cases which account for $4.2 \%$ in an extended study between 1991 -2004. African series showed case report of a 30-year-old male UK resident originally from Ghana and a 25-year-old Egyptian male, both were admitted to an emergency with history of right iliac fossa pain and diagnosed of schistosomal appendicitis in United Kingdom and Saudi Arabia respectively. [12, 13] This study confirmed that appendicitis can also be caused by schistosomiasis mostly in endemic African countries with isolated import cases in developed countries. Gastrointestinal involvement of schistosomiasis was reported in sigmoid colon 2 cases $(7.7 \%)$ and rectum in 3 cases $(11.5 \%)$. The infestation of sigmoid colon and rectum were not suspected clinically but histology confirmed on resection specimen of sigmoid colon and rectal biopsy for unspecified clinical impression. There is paucity of extensive data on schistosomiasis of sigmoid colon and rectum. However, case report from a 40-year-old man native of Angola who had immigrated 5 years previously was found to have schistosomiasis of the sigmoid colon on the clinical diagnosis of recurrent volvulus. [14] This is concordant with 47-yearold man with sigmoid megacolon in Saudi Arabia. [15] and Cao J et al reported 46 colonic schistosomiasis cases. [16] In this study, a case and 3 cases of schistosomiasis was found in the benign prostatic hyperplasia (BPH) and adenocarcinoma respectively. A case report from 65-year-old man with BPH and schistosomiasis was found in India [17] and case series of adenocarcinoma of the prostate with schistosomiasis in Tanzania. [18] Similar review was reported in Angola and Brazil. [19, 20] Urinary bladder schistosomiasis was seen in 111 cases which accounted for $86.0 \%, 10$ cases $(7.7 \%)$ of ureter, 4 cases (3.1\%) of urethra and a case (0.8\%) pyelonephritis. Similar findings were reported by other authors. [21-25] The myriad of these lesions stem from schistosomal eggs deposition which release protease that triggers granulomatous inflammatory response, fibroblast proliferation with mural fibrosis and inflammatory cells infiltrate comprising of eosinophils, lymphocytes, plasma cells and macrophages. Invasive squamous cell carcinoma is the commonest cancer associated with schistosomiasis of the urinary bladder accounted for 27 cases $65.8 \%$, followed by adenocarcinoma and high grade papillary urothelial carcinoma each accounted for 4 cases $9.7 \%$, and 2 cases (4.9\%) of invasive urothelial carcinoma. Similar review was reported by other authors in Nigeria and Egypt. [26, 27] The cancer was induced by chronic granulomatous inflammation with compensatory proliferation of transitional epithelial cells and regenerative process. The regenerative process leads to squamous metaplasia, dysplasia, carcinoma in situ and invasive carcinoma aided and abetted by plethora of growth factors, cytokines, chemokines and other bioactive substances that are produced by active immune cells. The activated immune cells also produce reactive oxygen species that are genotoxic and mutagenic. The resultant effects are uncontrolled increased cell survival, tissue remodelling and angiogenesis. Unresolved chronic granulomatous inflammation owing to unremitting release of protease might leads to maladaptive immune response and promotion of tumorigenesis. This is in sharp contrast to observation in Western countries, cigarette smoking and occupational carcinogens are the most important risk factors for urothelial carcinoma (UC) which represents the majority in developed countries. [28, 29] Thus, it is germane to evaluate patients for schistosomiasis in any organs especially in the endemic regions in Africa comprising of Saharan and Sub Saharan African countries.

\section{Conclusion}

Schistosomiasis of varieties of organ involvement have been histologically documented. Clinical sign and symptoms, history of swimming in the stagnant water bodies, irrigation ditches, urine and stool examination for eggs, antigen detection, serology and DNA testing should be employed in the diagnosis of schistosomiasis.

\section{References}

[1] Abiola FA, Babatunji EE, bolajoko IO, Abidemi P. Impact of human schistosomiasis in sub-Saharan Africa. The Brazilian Journal of Infectious Diseases. 2015; 9 (2): 196-205. 
[2] P. J. Hotez, M. Alvado, and M.-G. Bas'ãnez. The global burden of disease study 2010: interpretation and implications for the neglected tropical diseases. PLOS Neglected Tropical Diseases. 2014; 8 (7): e2865.

[3] Kiran Singh, DalhatuMuddasiru, Jitendra Singh. Current status of schistosomiasis in Sokoto, Nigeria. Parasite Epidemiology and Control. 2016;1(1): 239-244.

[4] Global Health Estimates 2016: Deaths by Cause, Age, Sex, by Country and by Region, 2000-2016. Geneva, World Health Organization; 2018.

[5] Ahmed SA, Mohammed U, Sanda RB, MakamaJ, Shehu MB, Ameh EA, Mayun AA. Schistosomiasis of the appendix in a tertiary hospital in northern Nigeria: A 22-year review. J Lab Physicians. 2014; 6: 18-21.

[6] Gali BM, Nggada HA, Eni EU. Schistosomiasis of the appendix in Maiduguri. Trop Doct 2006; 36: 162-3.

[7] Adebamowo CA, Akang EE, Ladipo JK, Ajao OG. Schistosomiasis of the appendix. Br J Surg 1991; 78: 1219-21.

[8] Abiodun, Afolabi Benjamin, Momoh, Martins Osadolor, Abiodun, Adejoke Deborah. Appendicular Schistosomiasis in a Nigerian Woman. International Journal of Tropical Disease\& Health. 2018; 34 (3): 1-5.

[9] Ojo OS, Udeh SC, Odesanmi WO. Review of the histopathological findings in appendices removed for acute appendicitis in Nigerians. J R CollSurg Edinb 1991; 36: 245-8.

[10] AO Adisa, AEOmonisi, SA Osasan, OI Alatise. Clinicopathological review of schistosomal appendicitis in southwestern Nigeria. Surgical Gastroenterology. Tropical Gastroenterology 2009; 30 (4): 230-232.

[11] Badmos KB, Komolafe AO, Rotimi O. Schistosomiasis presenting as acute appendicitis. East Afr Med J 2006; 83: 528-32.

[12] CallistoMadavo and HishamHurriez. Schistosomiasis of the appendix. J R Soc Med. 2006; 99(9): 473-474.

[13] Aldossary MY, Almabyouq F, Mashhour M, Hassan K. Schistosomal appendicitis presenting as acute peritonitis: A case report and literature review. J Health Spec 2017; 5: 225-7.

[14] Mourra, N, Lesurtel, $\mathrm{M}$ and Flejou, JF. Chronic schistosomiasis: an incidental finding in sigmoid volvulus. $\mathrm{J}$ Clin Pathol 2006; 59: 111-112.

[15] Amer R. Alzahrani, HomoudAlawfi, Sara Almeman, ThamerAltayeb, and Hasan M. Al-Dorzi. Megacolon due to Chronic Schistosomiasis: A Case Report and Review of Literature. Hindawi. 2019. 1 (1): 1-3.

[16] Cao J, Liu WJ, Xu XY, Zou XP. Endoscopic findings and clinicopathologic characteristics of colonic schistosomiasis: A report of 46 cases. World J Gastroenterol 2010; 16 (6): 723 727.
[17] Ruchi Sharma, Sadhana D Mahore, HrushikeshKolhe, Revati Patil, Kalpana Bothale, Anne Wilkinson. Schistosomiasis in prostate. A case report. Int J of Allied Med Sci and Clin Res. 2015; 3 (3): 293-297.

[18] Mazigo HD, Zinga M, Heukelbach J, Rambau P. Case series of adenocarcinoma of the prostate associated with Schistosomahaematobium infection in Tanzania. J Global Infect Dis 2010; 2: 307-9.

[19] Jacinta Chaves Figueiredo, Joachim Richter, NiloBorja, Antonino Balaca, Sandra Costa, Silvana Belo et al. Prostate adenocarcinoma associated with prostatic infection due to Schistosomahaematobium. Case reportand systematic review. Parasitol Res. 2014; 114 (2): 4250-9

[20] Albert Bacelar; Larissa G. M. C. Castro; Aristides Cheto de Queiroz; Eduardo Café. Association between prostate cancer and schistosomiasis in young patients: a case report and literature review. Braz J Infect Dis. 2007; 11 (4): 520-522.

[21] Ghoneim, M. A. Bilharziasis of the genitourinary tract. BJU International. 2002; 89( 1): 22-30.

[22] Rambau PF, Chalya PL, Jackson K. Schistosomiasis and urinary bladder cancer in North-Western Tanzania : a retrospective review of 185 patients. 2013 ; 19-24.

[23] Palumbo E. Association between Schistosomiasis and Cancer A Review. 2007; 15 (3): 145-8.

[24] Azami MA, Elalami I, Siati A, Lamalmi N. An unusual presentation of ovarian dermoid cyst : a case report and review of literature. 2018; 61 (4): 529-32.

[25] Hajissa K, Muhajir AEMA, Eshag HA, Alfadel A, Nahied E, Dahab R, et al. Prevalence of schistosomiasis and associated risk factors among school children in Um-Asher Area, Khartoum, Sudan. BMC Res Notes. 2018; 11 (1): 1-5.

[26] Eni, UE, Na'aya, H Nggada, H, Dogo, D Carcinoma Of The Urinary Bladder In Maiduguri: TheSchistosomiasis Connection. The Internet Journal of Oncology. 2007; 5 (2): 17.

[27] Noha S. Ahmed, Sheren F. Mahmoud, Elnisr R. Mohamed and Refaat M. Khalifa. Histopathological analysis of Schistosomahaematobium metaplasia of the urinary bladder. J. Egypt. Soc. Parasitol. 2017; 47 (1): 211-218.

[28] ZeegersMP, Tan FE, E Dorant, E van Den Brandt, PA. The Impact of Characteristics of Cigarette Smoking on Urinary Tract Cancer Risk: A Meta-Analysis of Epidemiologic Studies. Cancer. 2000 Aug 1; 89 (3): 630-9.

[29] Ploeg M, Aben KK, Kiemeney LA. The present and future burden of urinary bladder cancer in the world. World J Urol. 2009; 27 (3): 289-293. 